\title{
Study on the Maximum Allowable Concentration of Various Inorganic Acids
}

\author{
by \\ Masanao KIDOKORO* and Isamu SHIMOYAMA*
}

\section{Introductory}

Restrictions hitherto placed on the maximum allowable concentrations of various inorganic acids which are handled in chemical factories are calculated on the base of their influence on the respiratory organs, not from the acid corrosion of teeth. From this point of view, the authors have attempted at looking into the maximum allowable concentrations of hydrochloric, sulphuric and nitric acids by means of the electron microscopic photography. Experiments were also carried out to find out a relationship between the acid corrosion of teeth and the acid quantity contained in the air.

\section{Techniques and Materials}

1. Acid concentration in the initial stage of teeth corrosion

a) Materials: Lower anterior teeth which showed no defect to the naked eye were carefully rinsed with water with any deposit removed and they were made dry after 24 hours by means of alcohol of official standards. They were wrapped by paraffin except a window of $4 \mathrm{~mm} \times 4 \mathrm{~mm}$ near the labial incisal edge, out of which a replica was prepared. It was subjected to the electron microscopic photography with power of 2,000 .

b) Acids for test use: $1 \%$ standard solutions were prepared of hydrochloric, sulphuric and nitric acids which were further diluted by the addition of distilled water with $\mathrm{pH} 7.0$ for which $\mathrm{CO}_{2}$ had been previously traced. These solutions were prepared into liquids with $\mathrm{pH}$ from 5.0 to 6.3 by means of the glass electrode $\mathrm{pH}$-meter, at a temperature of $36.5^{\circ} \pm 0.5^{\circ} \mathrm{C}$ by means of an electric thermostat.

c) Technique: Each liquid with the measurement of $100 \mathrm{cc}$ was put in a polyethylene bottle with the content of $250 \mathrm{cc}$, into which a tooth was placed each. These bottles were shaken for 8 hours at an interval of every hour. Following the shaking process, the teeth were rinsed with water and replicas were prepared from the window sections. $2000 \times$ electron microscope photography was taken of the portions corroded with these acids. The same experiments were repeated for 8 hours at the rate of 1 , $2,4,7,16$ and 32 times respectively.

d) Electron microscope photography: For this purpose, the two-step replica method was adopted with use of acethylcellulose and low-fusing paraffin (Bioden RFA). Replicas prepared from the corroded sections were treated with the chrome evaporation

* 木所正直, 下山勇: Dept. of Hygiene, Nihon Univ. School of Dentistry (Director: Prof. Bogo KOINUMA) 
at the projection angle of $40^{\circ}$ for shadow effects and $2000 \times$ electron microscope photography was undertaken by HITACHI HU-10 electron microscope (the resolving power is $\left.10^{\circ} \mathrm{A}\right)$.

\section{Relationship between the quantities of acids in the air and those on the tooth surface}

By the use of an experimental apparatus (Fig. 1), $500 \mathrm{cc}$ of the test acid was taken in a container connected with the suction pump and a fume thus sucked up was induced into a spot where the two upper and lower anterior teeth were fastened by paraffin together with $\mathrm{pH}$ test papers, MR and TB. Then it was drawn through four pipes successively containing $50 \mathrm{cc}$ of the prescribed 0.1 caustic sodium and the solutions in the pipes were titrated with 0.1 hydrochloric acid and their $\mathrm{pH}$ values were measured in terms of decoloration. The test acids used were $10 \%$ hydrochloric acid, $20 \%$ sulphuric acid and $5 \%$ nitric acid, and they were kept at the constant temperature of $21^{\circ} \mathrm{C}$ by means of a thermostat. Suctions were repeated five times, with 3001 at a time, and the average values were obtained of the results.

Fig. 1

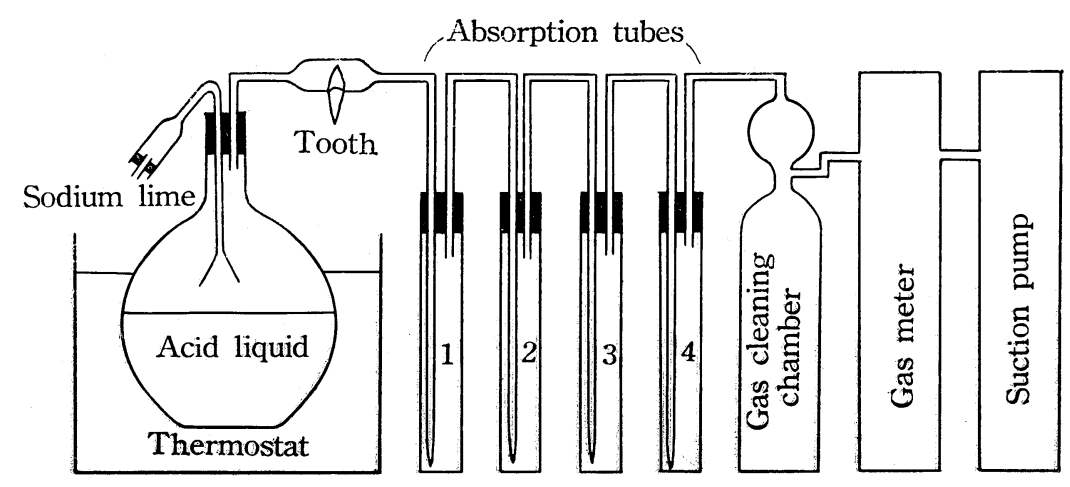

TABLE 7

Experimental Results

\begin{tabular}{|c|c|c|c|c|c|c|c|c|c|}
\hline Acids & \multicolumn{3}{|c|}{ Sulphuric acid } & \multicolumn{3}{|c|}{ Hydrochloric acid } & \multicolumn{3}{|c|}{ Nitric acid } \\
\hline Results & \multirow{2}{*}{$\mathrm{mg} / \mathrm{l}$} & \multicolumn{2}{|c|}{$\mathrm{pH}$} & \multirow{2}{*}{$\mathrm{mg} / \mathrm{I}$} & \multicolumn{2}{|c|}{$\mathrm{pH}$} & \multirow{2}{*}{$\mathrm{mg} / \mathrm{l}$} & \multicolumn{2}{|c|}{$\mathrm{pH}$} \\
\hline Frequency & & A & $\mathrm{B}$ & & $\mathrm{A}$ & $\mathrm{B}$ & & $\mathrm{A}$ & $\mathrm{B}$ \\
\hline 1 & 0.618 & 4.2 & 1.8 & 0.412 & 5.0 & 2.6 & 0.618 & 4.2 & 1.8 \\
\hline 2 & 0.756 & 3.8 & 1.4 & 0.549 & 4.4 & 2.0 & 0.549 & 4.4 & 2.0 \\
\hline 3 & 0.412 & 5.0 & 2.6 & 0.412 & 5.0 & 2.6 & 0.549 & 4.4 & 2.0 \\
\hline 4 & 0.481 & 4.8 & 2.4 & 0.481 & 4.8 & 2.4 & 0.687 & 4.0 & 1.6 \\
\hline 5 & 0.481 & 4,8 & 2.4 & 0.343 & 5.2 & 2.8 & 0.481 & 4.8 & 2.4 \\
\hline
\end{tabular}




\section{Experimental Results and Considerations}

\section{Acid concentration for the start of corrosion}

Results of a series of tests described in the foregoing section have furnished the following table for comparison purposes (Fig. 2) :

\begin{tabular}{|c|c|c|c|}
\hline & Initial stage & Fair progress & Pronounced corrosion \\
\hline Hydrochloric acid & pH 5.8 & $\mathrm{pH} 5.4$ & pH 5.0 \\
\hline Sulphuric acid & $\mathrm{pH} 5.8$ & & $\mathrm{pH} 5.0$ \\
\hline Nitric acid & $\mathrm{pH} 5.8$ & $\mathrm{pH} 5.4$ & pH 5.0 \\
\hline & & & $\begin{array}{l}\text { (much more pronounced } \\
\text { than that of hydrochloric } \\
\text { acid) }\end{array}$ \\
\hline
\end{tabular}

Fig. 2. Corrosion after Eight Hours

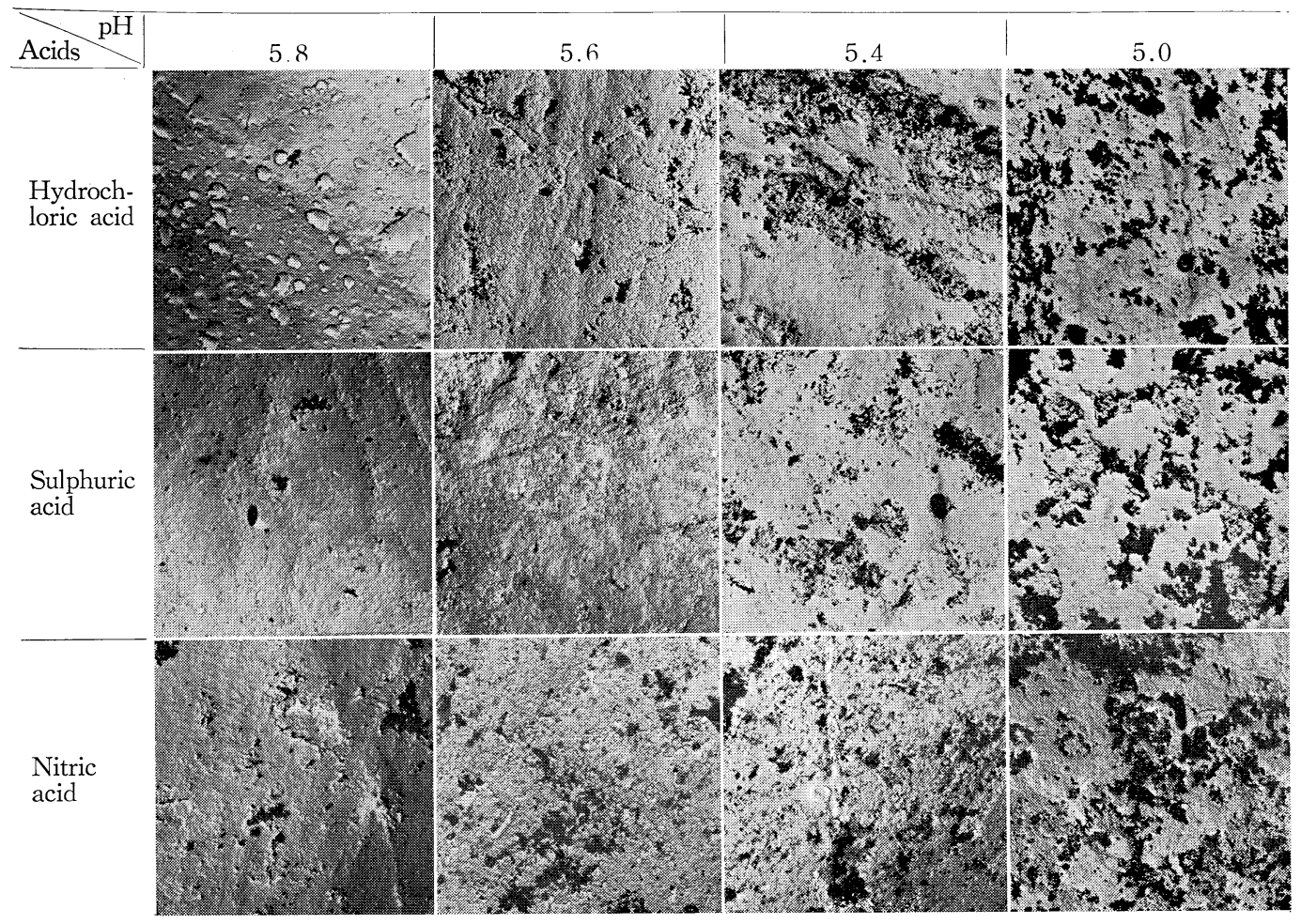

In the case of an eight-hour test repeated twice, no corrosion is observed on any of the three sample acids over $\mathrm{pH} 6.0$ (Figs. 3, 4 and 5). In the same test repeated four times, only nitric acid shows a slight corrosion over $\mathrm{pH}$ 6.0. In another set of the same test repeated eight times, hydrochloric acid shows a slight corrosion, sulphuric acid much lesser degree of acid corrosion and nitric acid quite pronounced corrosion. A slight degree of corrosion also takes place $\mathrm{pH}$ 6.1. In those tests repeated sixteen times, 
hydrochloric acid shows a fairly advanced stage of corrosion at $\mathrm{pH} 6.0$, sulphuric acid a degree of corrosion somewhat advanced than that of eight- time repetition but shows no corrosion at $\mathrm{pH}$ 6.1. Nitric acid shows a high corrosion at $\mathrm{pH} 6.0$ and a slight degree of corrosion at $\mathrm{pH}$ 6.2. Although the same tests were repeated for thirty-two times, none of the acids shows any change attributable to the acid effect.

Flg. 3. Corrosions by Sulphuric Acid

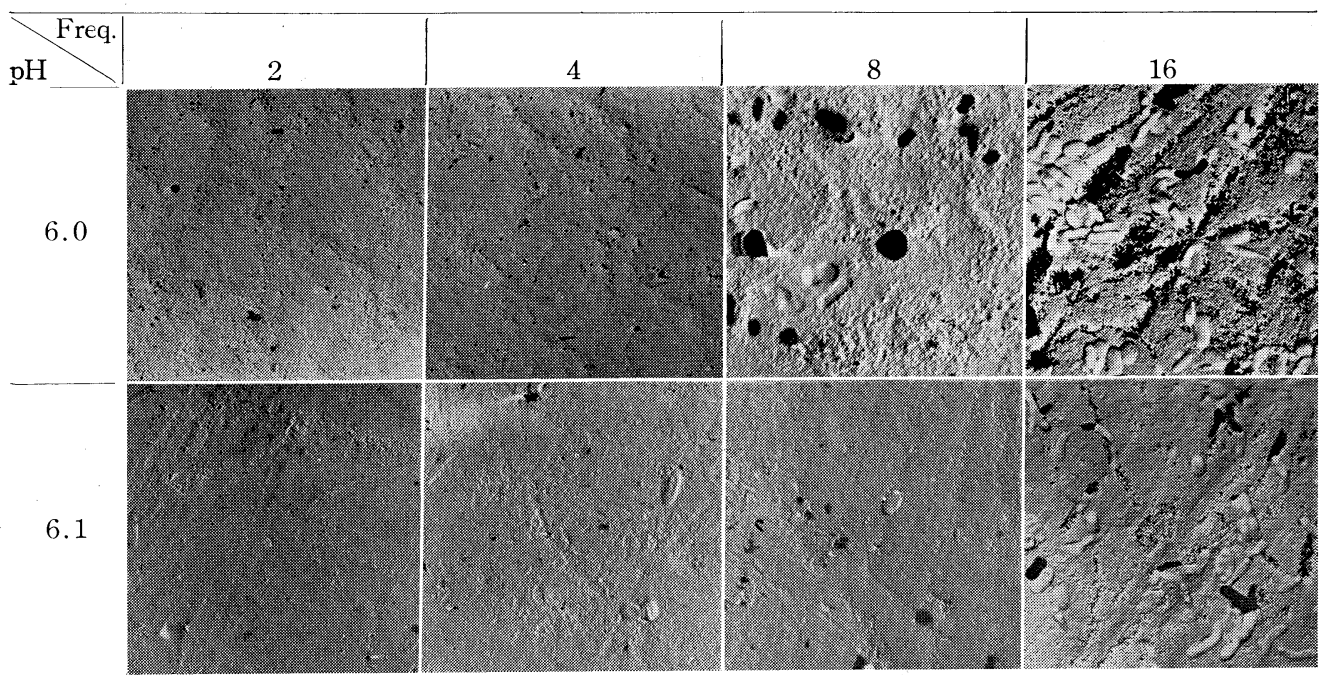

Fig. 4. Corrosions by Sulphuric Acid

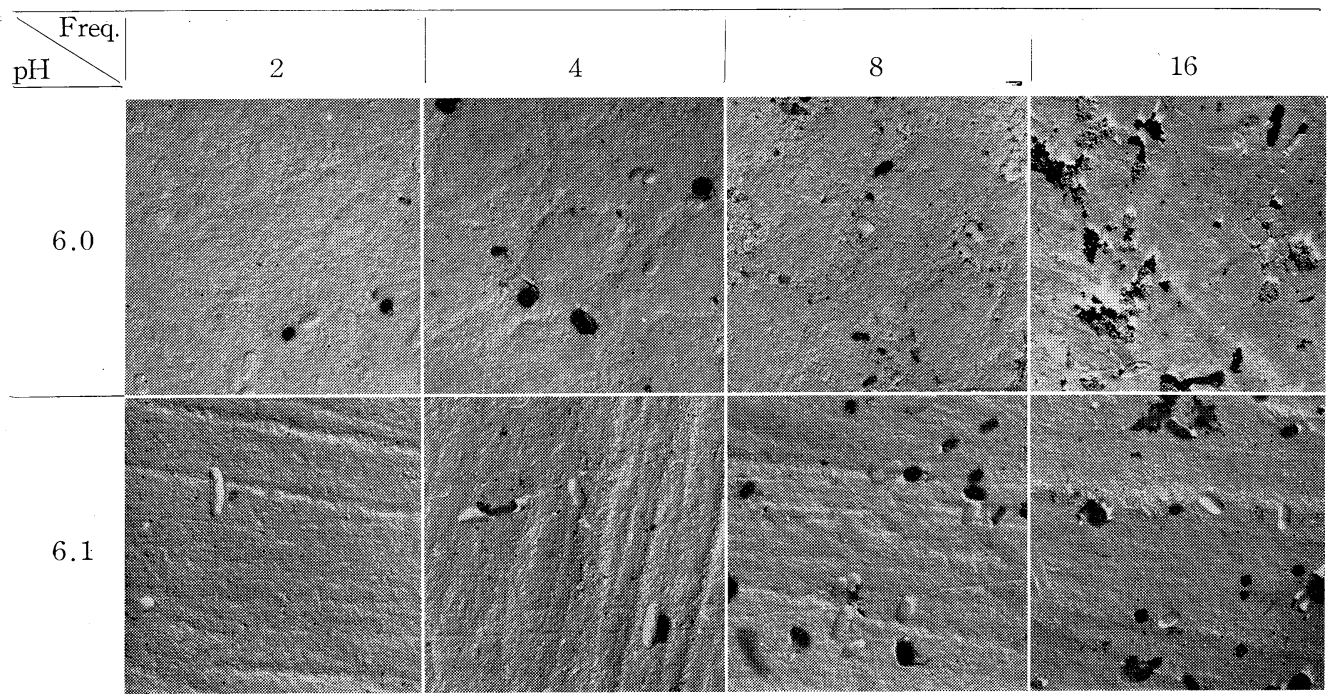

2. The quantities of acids in the air and acid concentration on tooth surface

The result of a test under this heading is given in Table 2. The value of $\mathrm{A}$ in the section $\mathrm{pH}$ was rendered $\mathrm{pH} 7.0$ by the addition of distilled fwater prior [to the 
Fig. 5. Corrosions by Nitric Acid

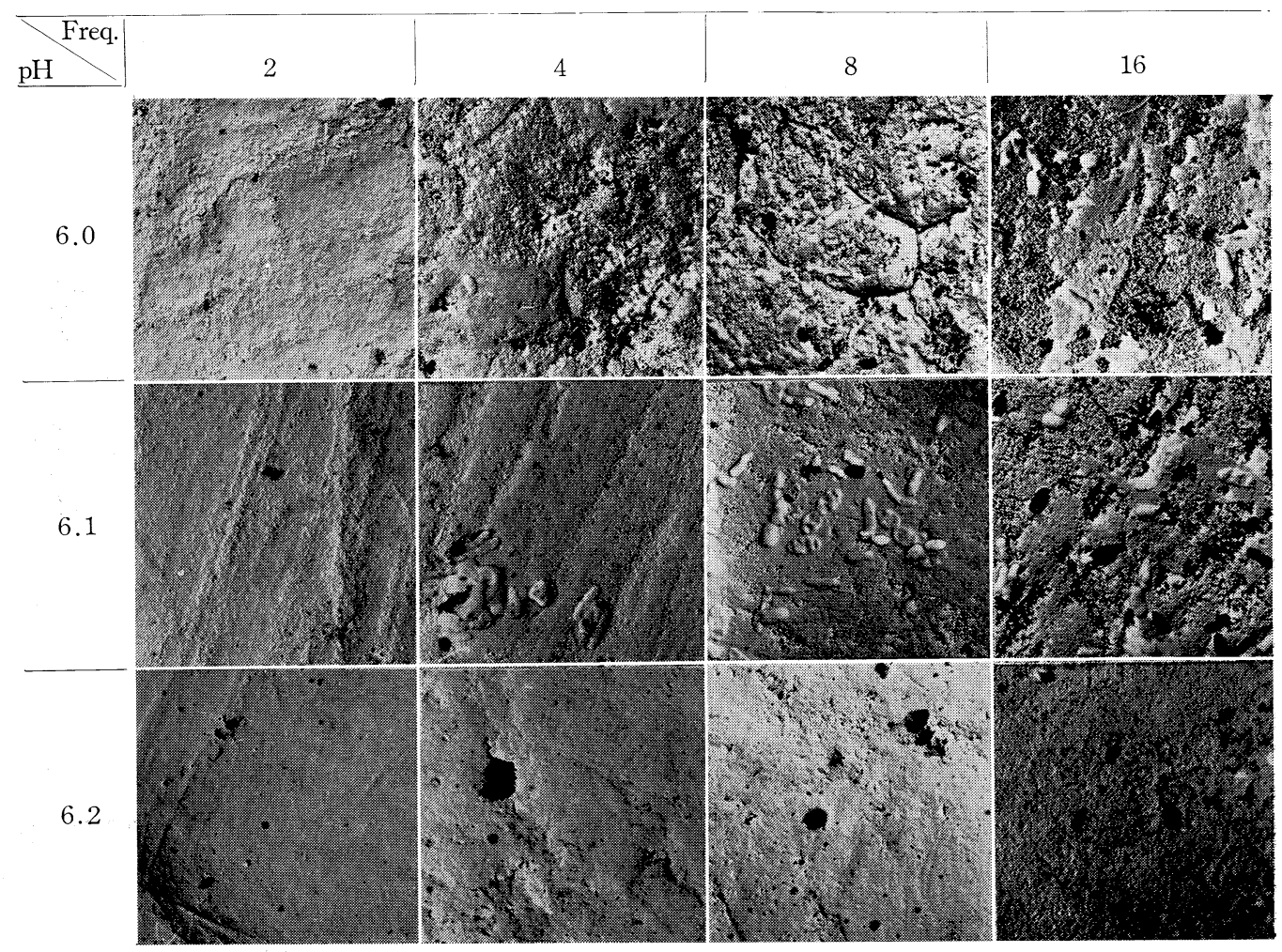

TABLE 2

Logarithm Table Readings

\begin{tabular}{|c|c|c|c|c|c|c|}
\hline \multirow{2}{*}{$\underbrace{\text { Acid quan- }}_{\mathrm{pH}}$} & \multicolumn{2}{|c|}{ Hydrochloric acid } & \multicolumn{2}{|c|}{ Sulphuric acid } & \multicolumn{2}{|c|}{ Nitric acid } \\
\hline & A $\mathrm{mg} / 1$ & B $\mathrm{mg} / \mathrm{l}$ & A $\mathrm{mg} / \mathrm{l}$ & B $\mathrm{mg} / 1$ & A $\mathrm{mg} / 1$ & B $\mathrm{mg} / \mathrm{l}$ \\
\hline 5.8 & 0.251 & 0.111 & 0.232 & 0.098 & 0.265 & 0.126 \\
\hline 6.0 & & & 0.219 & 0.082 & & \\
\hline 6.1 & 0.186 & 0.084 & & & & \\
\hline 6.2 & & & & & 0.174 & 0.084 \\
\hline
\end{tabular}

beginning of the test. On the other hand, the value of $\mathrm{B}$ was non-treated in TB.

For $10 \%$ hydrochloric acid, $\mathrm{pH} 4.2$ and $\mathrm{pH} 1.8$ are obtained respectively in A and $\mathrm{B}$ at the first trial where the acid concentration in the air is $0.618 \mathrm{mg} / \mathrm{l}$. In the subsequent tests, $\mathrm{pH}$ values for $\mathrm{A}$ and $\mathrm{B}$ go upward with a decrease of acid concentration in the air. At the fifth trial, $\mathrm{A}$ is $\mathrm{pH} 4.8$ and $\mathrm{B}$ is $\mathrm{pH} 2.4$ respectively where the acid in the air is $0.481 \mathrm{mg} / \mathrm{l}$. 
For $20 \%$ sulphuric acid, $\mathrm{A}$ is $\mathrm{pH} 5.0$ and $\mathrm{B}$ is $\mathrm{pH} 2.6$ at the first trial where the acid in the air is measured to be $0.412 \mathrm{mg} / \mathrm{l}$. There are $\mathrm{pH} 5.2$ and $\mathrm{pH} 2.8$ respectively at the fifth trial. With $5 \%$ solutions, they are respectively 4.2 and 1.8 for. A and $\mathrm{B}$ at the first trial. Finally, at the fifth trial they are 4.8 and 2.4 respectively.

3. Acid concentration in the air starting the tooth corrosion

The test was carried out with a view to looking into a relationship between the acid concentration in the air and $\mathrm{pH}$ value on the surface of tooth (Table 2). The figures thus obtained are based on the same test undertaken for five times on each test acid. The values for $\mathrm{A}$ which have been set at $\mathrm{pH} 7$, in each of the three test acids, have shown nearly twice as much as those for $\mathrm{B}$ which are non-treated.

\section{Discussion}

As is shown by Table 2, a difference between the values for $\mathrm{A}$ and $\mathrm{B}$ in which the acid concentration in the air starts the corrosion of teeth is due to whether the $\mathrm{pH}$ on the surface of teeth receives some alleviating effect by saliva or not. Therefore, it may be concluded that this alleviating effect of saliva plays an important role in the preventive function against the acid corrosion. In industries where acids are handled in their operations, the workers are exposed to the conditions similar to B described above through their talk and respiration. When the values of the three test acids are converted into the amount of hydrochloric acid, the acid concentration in the air which starts the corrosion of teeth is estimated to be anywhere around $0.08 \mathrm{mg} / \mathrm{l}$.

\section{Conclusion}

As a result of a series of tests in which the attempt has been made to ascertain the possible acid concentration in the air which starts the corrosion of teeth, the findings point out a conclusion that the acid concentration in the working atmosphere of industries where the acids are handled should be checked under $0.08 \mathrm{mg} / \mathrm{l}$ from a point of view of oral hygiene. Therefore, the recommendation made by A.G.G.I.H. for the allowable maximum concentration of acid in the air which has a range from 0.007 to $0.03 \mathrm{mg} / \mathrm{l}$ (though it is made from a point of view of respiratory organ disturbances) may be regarded to be also justified in the case of teeth under an exposure of long duration.

\section{References}

1) Kornuma, Bogo: Occupational Diseases and Industrial Poisonings, Ryu-kon Co., 1938.

2) Asada, Yoshiya : Ph Value of Saliva and Blood Pressure of Workers in Sulphurous Gas Factory Shika-Geppo, Vol. 23, No. 4 (1943).

3) Kubota, Shigetaka : Occupational Diseases in Recent Years, Labor Science Research Institute, 1943.

4) Labor Sanitation Dept., National Health Board: Handbook of Allowable Concentrations of Obnoxious Substances, 1954.

5) Hamasaka, I. : Study on Tooth Corrosion, Studies in Medicine, Vol. 23, No. 2 (1953).

6) Yamamoto, H. : Dental Hygiene in Industrial Factories, Journal of Kyushu Hygiene Society, Vol. 7, No. 12 (1953).

7) OnISHI, M. and Kondo, W., Experimental Study of Tooth Corrosion and its Anti-acid Effect, Journal of Oral Hygiene Soc., Vol. 2, No. 2.

8) Nagata and Shimizu : Study on Dental Hygiene in Certain Mining Plant, Journal of Oral 
Hygiene Soc., Vol. 6, No. 2 (1956).

9) Katayama T. : Oral Inspection of Workers in Sodium Plant, Journal of Oral Hygiene Soc, Vol. 3 (1955).

10) Nishimura, So and Fujimura: Notes on Tooth Corrosion with Reference to its Origin, Journal of Oral Hygiene Soc., Vol. 6, No. 4 (1957).

11) Tsuchiya and OKAdA: On Shadowing Method, Journal of Electron Microscope, Vol. 1, No. 1 (1951).

12) Matsumiya, S. and Takuma, S. : Electron Microscopic Atlas of Teeth, Tokyo ;Dental College Press, 1941.

13) Terada, S. Kusama, M. and Hirota, K. : Alleviating Effect of Human Saliva, Journal of Oral Pathological Soc., Vol. 15 (1941).

14) A.M.A. Arch. Indust. Health: Threshold Limit Values for 1959, $20: 3$ (1959). 